\title{
Mars' nordligste feltgeolog - Phoenix Mars Lander
}

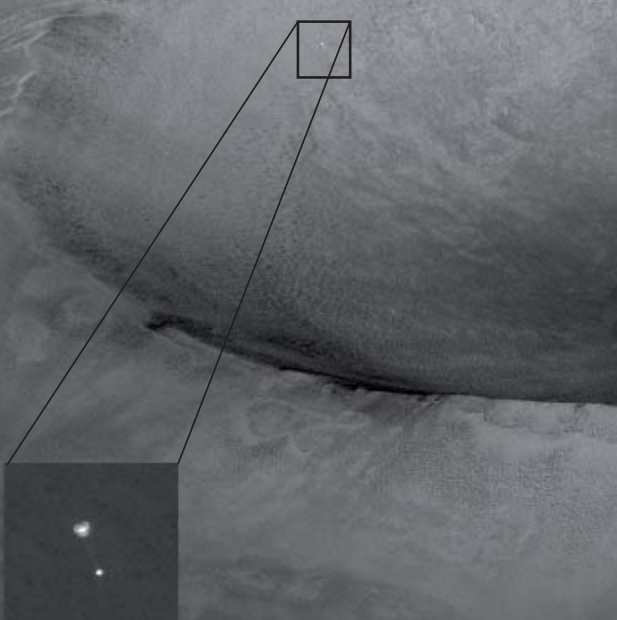

Ligesom forskere og ingeniører i kontrolrummet i Tuscon Arizona fulgte HiRISE - den nyeste satellit i kredsløb om Mars - Phoenix’landing opmcerksomt. Det resulterede i dette billede taget på $760 \mathrm{~km}$ afstand, hvor Phoenix i en højde af $13 \mathrm{~km}$ over overfladen fløj gennem den tynde Mars-atmosfere, før den i 1 km's højde afkoblede faldskcrmen og ved hjcelp af raketmotorer bremsede resten af vejen ned. Heimdall-krateret $i$ baggrunden er $10 \mathrm{~km}$ i diameter og ligger $20 \mathrm{~km}$ fra landingsstedet. (Copyright: Courtesy NASA/JPL /University of Arizona)

Af ph.d.-studerende Gro Birkefeldt Møller Pedersen, Geologisk Institut, Aarhus Universitet

Lastet med mikroskoper, ovne, en skovl, en vejrstation og et mindre kemilabortorium er feltarbejdet gået igang for Phoenix. For første gang kortlægges det polare klima ved Mars' nordpol, og Phoenix har afsløret is i 5 cm's dybde og undersøgt kemien af den lokale permafrostjord.

Den 25. Maj 2008 landede Phoenix Mars Lander succesfuldt på vores røde naboplanet. Rejsen var startet den 4. august 2007, mens tilblivelsen af rumsonden har flere årtier på bagen. Phoenix instrumentering er nemlig baseret på to kuldsejlede missioner fra 1990'erne, og Phoenix Mars Lander er derfor passende nok blevet opkaldt efter den græsk mytlogiske fugl, som opstår af sine forfædres aske.
En historie om vand og liv

Men hvorfor alt det besvær for at lande i Mars' ekstreme arktiske egne, der ikke just er garant for langlivede missioner? Svaret er, at Mars' poler regnes for at være en vigtig brik i forståelsen af vandets historie på Mars og desuden et ideelt sted at observere årstidsvariationer og dermed Mars' klimatiske historie. Begge emner er led i NASA's overordnede mål for udforskningen af Mars.

Interessen for vand på Mars bygger på, at vand regnes for at være en afgørende forudsætning for liv. Samtidig har ekspeditioner til Mars siden 1960'erne vist, at der er gigantiske flodlejer, som bogstavelig talt har krævet oceaner af vand at forme, men hvor vandet er i dag, er en gåde. Tilstedeværelsen af flydende vand kræver, at Mars' klima har været meget anderledes i forhold til den kolde ørken, vi kender nu. I dag er vand nemlig ustabilt på Mars' overflade, pga. Mars' lave overfladetemperatur samt et atmosfæriske tryk på nogle få procent af de jordiske.

Det har været foreslået, at alt Mars' vand muligvis er fordampet som følge af klimaforandringer og dermed er sluppet ud i verdensrummet, fordi Mars' tyngdekraft har været for utilstrækkelig til at holde på atmosfæren. En anden teori går på, at en del af Mars' vand i dag eksisterer som permafrost i de aktiske egne og muligvis som grundvand, da tabet af vand i undergrunden er estimeret til at være minimalt.

Og det er netop her, at Phoenix er et vigtigt kort på hånden. I 2002 opdagede rumsonden, Mars Odssey ved hjælp af et gammastråle-spektrometer (GRS) nemlig, at der var store mængder $\mathrm{H}_{2} \mathrm{O}$ under overfladen i Mars' arktiske egne, og dermed blev disse områder særligt interessante, når man leder efter liv på Mars (se figuren øverst på næste side).

Derfor er Phoenix designet til at studere vand, kigge efter organiske molekyler i permafrost-jord og lede efter vigtige grundstoffer som kulstof, kvælstof og fosfor, som kan fortælle noget om mulighederne for liv.

Indtil videre har Phoenix fundet en basisk jordbund med is og en mængde næringsstoffer som natrium, kalium og magnesium samt det giftige og stærkt oxiderende stof percolat, der kendes fra de tørreste 
ørkner på Jorden. Fundet af perchlorat ved hjælp af instrumentet MECA kan være med til at forklare Mars’ oxiderede, røde støv, men kan hverken be- eller afkræfte muligheden for liv. En stærk koncentration af pechlorat kan være hæmmende for eksistensen af liv, men fra Atacama-ørkenen i Chile kendes mikrober, der lever af at nedbryde perchlorat, og dermed bruger stoffet som energikilde.

\section{Phoenix' feltgrej}

Som for alle andre feltgeologer gælder det om at have feltudstyret i orden. Især når man er mere end 100 mio. km hjemmefra og rent faktisk ikke er designet til at tage turen hjem. Af samme grund bliver alle analyser taget i felten, hvorfor Phoenix’ udstyr ikke er "normaludstyr" for geologer. Forskere fra hele verden har samarbejdet om at udvikle det, inklusive forskere fra Aarhus Universitet og Københavns Universitet.

Phoenix er immobil og derfor ikke en rover - men derimod en lander. For at få fat i prøver bruger den sin 2,35 m lange robotarm (RA), hvorpå der er fastmonteret en skovl og et kamera (RAC) (figuren øverst på side 7). Skovlen er designet, så den kan grave sig en halv meter ned i løs Marsjord, og kanten af skovlen er så skarp, at den kan skrabe prøver af isrig permafrostjord. Samtidig giver RAC'en detaljerede bille-
2001 Mars Odyssey Røntgenspektrometer

Nordpolen vandkort

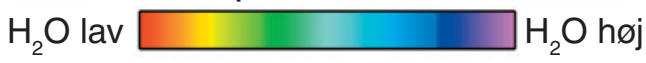

Koncentrationen af vand ved Mars' Nordpol målt af Marssatelliten, Mars Odysseys, Gamma Ray Spectrometer (GRS). Phoenix' landingssted er ved 68 grader nord, og 233 øst (= -127), hvor koncentrationen af $\mathrm{H}_{2} \mathrm{O}$ er høj tce på overfladen.

(Copyright: modificeret efter NASA/JPL/ University of Arizona)

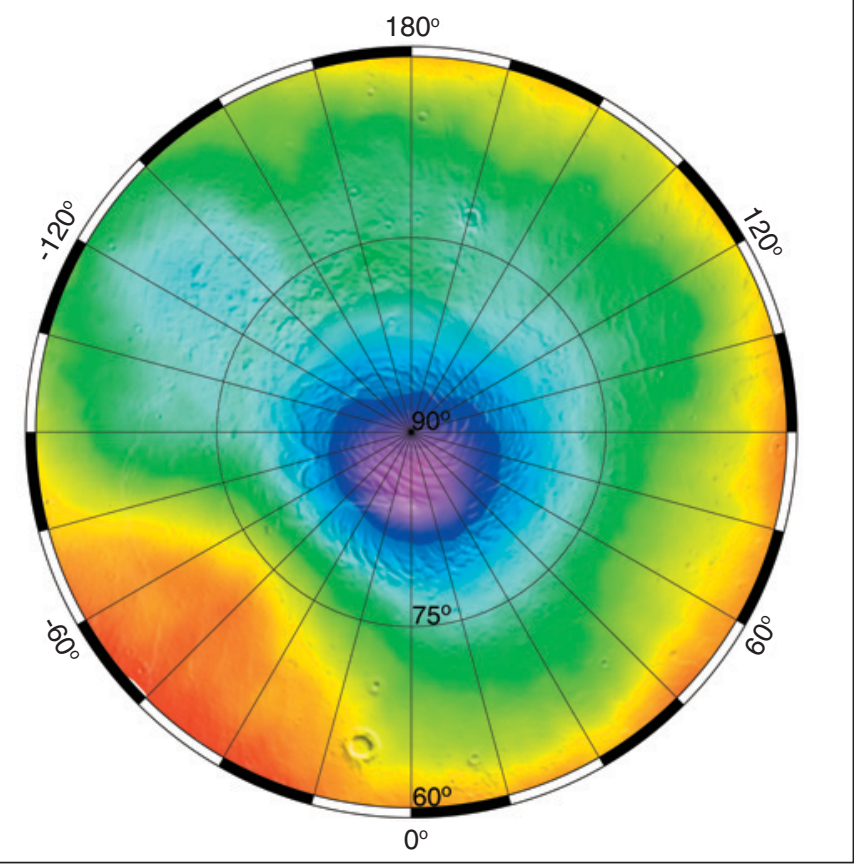

der af prøverne samt undersøger de huller, Phoenix graver, med hensyn til lagdeling og tekstur. Bagefter kan prøverne analyseres med henblik på kemiske, fysiske og optiske 


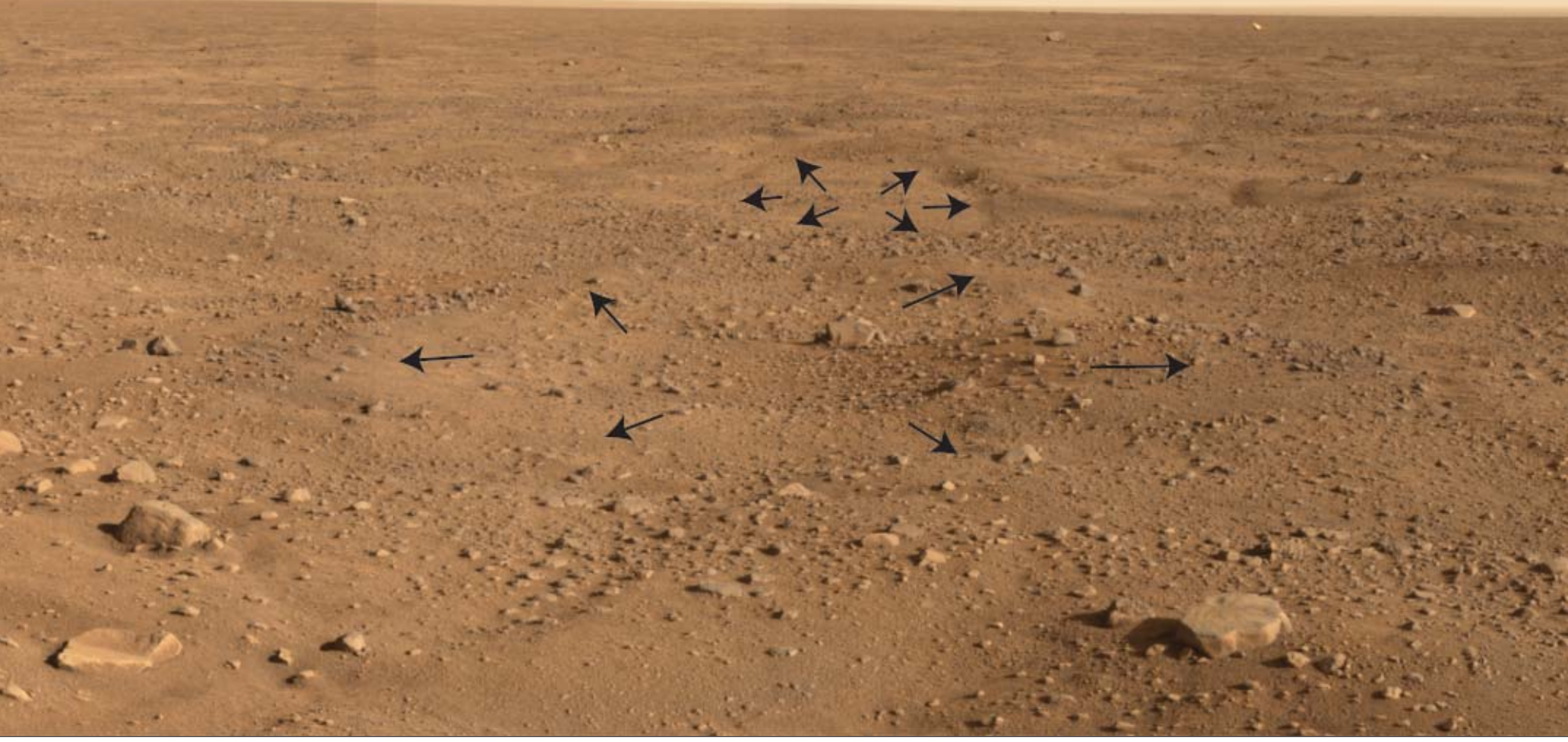

Phoenix' omgivelser set gennem kamerat SII. Billedet afslører meterstore permafrost-polygoner markeret med sorte pile. (Copyright: NASA/ $J P L-C a l t e c h / U n i v e r s i t y$ of Arizona/Texas A\&M University)

egenskaber ved hjælp af instrumenterne TEGA og MECA. TEGA består af 8 ovne, som kan opvarmes til mere end $1.000{ }^{\circ} \mathrm{C}$, og som er tilkoblet et massespektrometer, der analyserer de gasser, som ved opvarmningen fordamper blandt andet med hensyn til organiske molekyler.

Da NASA den 31. juli 2008 offentliggjorde, at man har smagt på Mars’ vand, var det altså isrig jord, som var blevet opvarmet i TEGAs ovne, hvorved vanddamp blev registreret i massespektrometeret. Prøverne kan også analyseres med hensyn til varmeledningsevne, elektrisk ledningsevne, $\mathrm{pH}-$ værdi, iltningsevne og salinitet ved hjælp af instrumentpakken MEGA.

\section{Dansk design}

Det danske bidrag består henholdsvis af en vindmåler, telltalen, og et kalibreringstarget til farvekameraet, SII.

Telltalen hører til den pakke af instrumenter, som undersøger det polare klima og er en snedig letvægter af en vindmåler, der viser vindretning og styrke ved affotografering af et spejl, som genspejler et meget let lod ophængt i nogle fibre. Da trykket på Mars overflade er $1 \%$ af det jordiske tryk, er det ekstremt svært at måle vindsstyrken. Instrumentet skal nemlig være meget sensitivt, og det har betydet, at det århusianske bidrag er det første instrument på Mars, der skal målevindsstyrken (figuren nederst på næste side).

Versioner af det københavnske instrument har derimod besøgt Mars’ overflade tre gange siden 1996, hvor Pathfinder som den første rover kørte rundt på Mars’ overflade. Kaliberingstarget er meget vigtigt for at få at farveægte billeder, som skal bruges til identificering af mineraler og vanddamp. Det har hidtil været problematisk, da Mars er støvet, og alt på rumsonden støves til med tiden. Erfaringen med tidligere kalibreringstargets har vist, at næsten alt Mars'støv er magnetisk, og det nye target på Phoenix er derfor indrettet så smart, at magneter friholder farvereferencerne for støv.

\section{Phoenix' endeligt}

Modsat historien fra den græske myte, dør Phoenix ikke i et flammehav, men forventes at fryse ihjel, når vinteren trænger sig på ved Mars’ nordpol. Efterhånden som sommeren ved Mars nordpol går på held, bliver det begrænset, hvor meget energi Phoenix' solpaneler kan optage, og rumsondens aktiviteter vil gå fra fuld arbejdstid på 8-9 timer til nogle få timer i oktober, og det er muligt, at Phoenix i november kun arbejder hver anden dag.

Det er usikkert, præcist hvordan og hvornår Phoenix dør. Et scenario er, at sonden dør, når det første $\mathrm{CO}_{2}$-sne falder, men risikoen for, at det er den lave temperatur, eller manglende energi forinden, der har sat en stopper for Phoenix aktiviteter, er en reel mulighed.

Dog er ét sikkert; forskere fra hele verden vil entusiastisk følge de sidste signaler fra Mars' arktiske egne for at blive lidt klogere på Mars’ nordligste mysterier. 


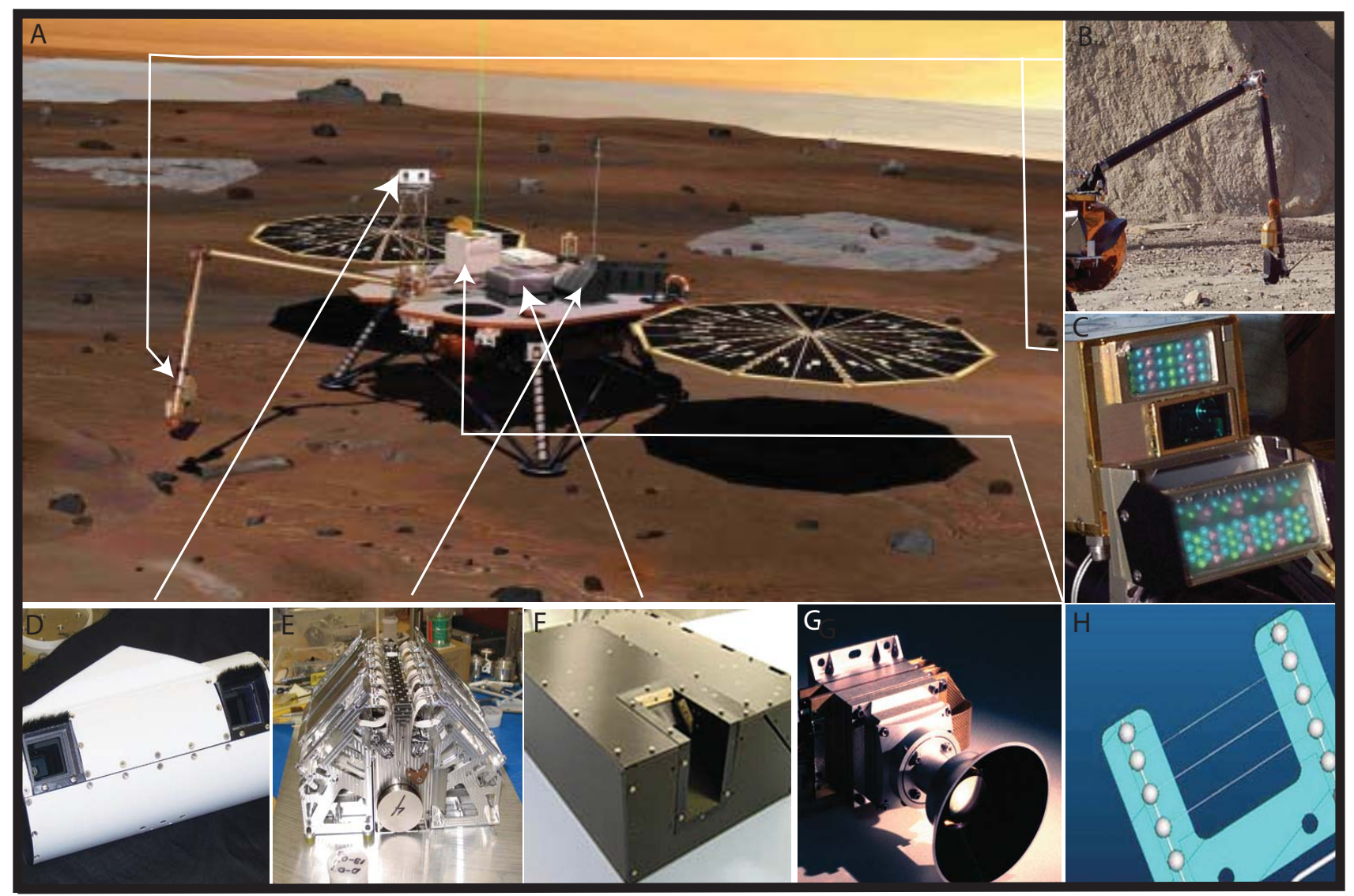

Videnskabelige instrumenter på Phoenix. A) Kunstnerisk illustration af Phoenix Mars Lander lavet af Corby Waste B) Robotarm (RA) bruges til at grave grøfter samt tage de prøver af jordbunden, der skal analyseres af TEGA og MEGA. C) Kamera på robotarm (RAC) kan levere ncerbilleder af Marsoverfladen, gravede grøfter og de prøver, som bliver indsamlet ved hjœlp af robotarmen D) Phoenix stereoskop (SSI) tager højtopløslige stereografiske panoramabilleder af landingsstedet for at få et overblik over geologien og for at forbedre udførslen af gravningen samt for at lave atmosfceriske målinger af støv og skyer. E) Thermal and Evolved Gas Analyzer(TEGA) består af 8 små ovne, som opvarmer prøver indsamlet med robtarmen og samtidig med, at energiforbruget måles. De gasser som fordamper, bliver via af et masespektrometer analyseret med henblik på den kemiske sammenscetning. F) Mikroskopi-, elektrokemi-, og konduktivitetsanalysator (MEGA) bruges til at undersøge pH-vœrdien, saltindhold og kemisk sammensætning. Desuden kan MECA undersøge prøverne ved hjcelp af et optisk mikroskop, samt et 'Atomic Force Micoscope'. Den thermale og elektriske konduktivitet kan også måles. G) Mars Descent Imager (MARDI) er et kamera, der under landingen tager højtopløselige farvebilleder af landingsstedet H) Meteologisk station (MET) måler dagligt vejret på Mars og består af temperatur- og trykmålere samt et LIDAR-instrument. LIDARinstrumentet består af en laser, der måler hvor meget af laserens lys der bliver spredt som følge af partikeltcetheden i atmosfcere. Dette kan vere med til at forstå udviklingenaf skyer, tåge og ikke mindst støvstorme, der har katestrofale følger for missioner til Mars. (Copyright: NASA/JPL-Caltech/University of Arizona/Texas A\&M University)

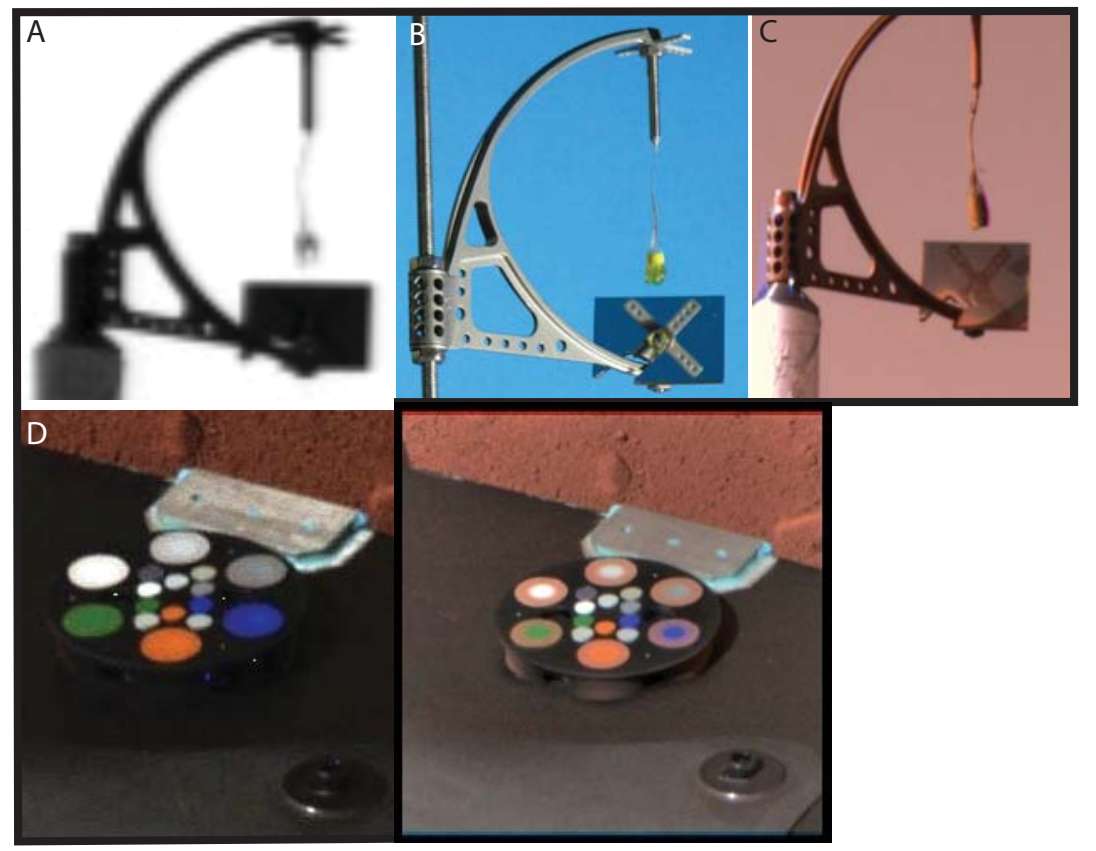

Det danske bidrag til Phoenixmissionen består af en vindmåler, telltalen (A-C) og et kalibreringtarget til stereokameraet ISS(D) A) Det første billede taget af vindmåleren efter Phoenix landede på Mars. Billedet blev taget for at tjekke, at telltalen var intakt efter den lange rejse til Mars

B) Billede af vindmåleren før Phoenix blev sendt til Mars. De ses, at det gule lod i spejlbilledet nederst prcecist er i midten af de retningsgivende tvcerbarer

C) Billede af vindmåleren efter 50 dage. Alt er rødt, og det ses, at tilstøvningen er markant.

$D-E)$ Billeder af kalibrerngstarget taget efter 2 og efter 20 dage. Man ser tydeligt, at de har samlet støv på kanten af de større farvereferencer, men samtididg er dele af kalibreringstarget stadig støvfrit som følge af magneternes placering.

(Copyright: NASA/JPL-Caltech/University of Arizona/Texas A\&M University) 